\title{
THE WORKPLACE EXPERIENCES OF WAITRESSES: EXPLORING THE NATURE OF EMOTIONAL LABOUR
}

\author{
Hannah Burton and Gemma Piercy \\ Labour Studies \\ University of Waikato
}

\begin{abstract}
In western developed economies, it is service work that is increasing most swiftly; thus as westerners, we are now more likely to experience this sector as either workers or clients (McDowell, 2009). This paper explores the working experiences of three young female waitresses in order to better understand the nature of the service sector in contemporary Aotearoa New Zealand society. This exploration incorporates a literature review covering the nature of interactive service sector work, as well as findings from in-depth interviews. The interviews focussed on the management-worker-customer triadic relationship that characterises interactive service work. The interviews were also used to explore how exploitation and alienation can be experienced in service sector workplaces. Each of the three women described times when they felt the power of others (employer, co-workers and/or customers) imposed upon them through poor management practices, workplace bullying and conflicts, and negative customer interactions. The findings demonstrate that their relationships with co-workers and managers were far more important than those with various customers, with the former being reported as the source of higher levels of workplace strain and distress. This challenges the literature's emphasis on both the customer and the employer negatively affecting workers when they are engaged in emotional labour. The interviews also indicated some support for Bolton and Boyd's critique of Hochschild's arguments on emotional labour, in relation to the young women's expression of agency. This is because the women expressed that there were times during their work in which they were able to make decisions independently. This is demonstrated by the moments of autonomy the women indicated they experienced when they were at work, as well as their descriptions of how they were able to exercise agency in relation to the flexible nature of their jobs. Most significantly, however, it was the young women's description of how they managed their emotional labour by holding their service sector identity as a temporary part of their life that indicated their internal agency and ability to resist the more negative aspects of their jobs. The women also indicated that the'enjoyable aspects of work', including the benefits of gaining industry based skills and qualifications, and finding personal enjoyment in positive interactions with customers, also helped mitigate the more negative aspects of their work life.
\end{abstract}

\section{Introduction}

In line with other first world countries, the New Zealand service industry is growing as other industries, such as traditional manufacturing, decline (Leidner, 1999; Edgell, 2011; McDowell, 2009). This growth necessitates the employment of an increasing proportion of the working population in service based industries including: retail, real estate, health care and social assistance, accommodation and food services. These areas account for four of the eight largest employing sectors of the working population in New Zealand (Careers NZ, 2006). Despite employing such large numbers, the experiences of those working in the service industry in New Zealand have gone largely undocumented from an industrial sociology or labour process theory point of view. This paper seeks to address this gap in the literature.

In this paper we discuss findings from research on service sector work that included interviews with three young women working as wait-staff in Hamilton, New Zealand. The paper begins by providing insights from the literature, then outlines briefly the research methodology employed. Next the findings are presented, followed by a discussion of the findings in relation to the literature.

\section{Literature Review}

Service work is the focus of a growing body of literature in cultural geography, employment relations, labour process analysis and industrial sociology. Much of this literature is very critical of service sector work in a range of ways. For example, it has been proposed that service work, when it is essentially performing tasks that people would have traditionally performed for themselves, emphasises master and servant roles, 're-cutting class boundaries' (McDowell, 2001). Anderson (2002), in a similar fashion to McDowell (2009), argues that the relationships between domestic workers and their employers reaffirm existing status relationships between the serving class and the upper classes. McDowell's (2009) discussion on disadvantages faced by those working in the service sector includes a lack of social mobility, a lack of stability and respect afforded from wider society, and also the requirement of service workers to use both their physical appearance and alterations to their personality as part of the labour power the employer purchases. These issues are explored in the literature through the concepts of emotional labour (Hochschild, 1983; Leidner, 1999; Edgell, 2011), precarious work 
(Vosko, MacDonald and Campbell, 2009) and the unique nature of the triadic relationship of interactive service work (McDowell, 2009; Hodson and Sullivan, 2012; Edgell, 2011).

In addition to societal prejudices about those working in service industries, there is also the issue of the precarious nature of service work that makes workers vulnerable and powerless in the employment relationship (Vosko et al., 2009). This is further complicated by the view of service work as unskilled through the theorisation of Ritzer and Lieder in relation to McDonaldisation or neo-taylorism (Edgell, 2011). How workers negotiate these areas of contradiction and conflict is still an emerging area of research. The majority of the existing research has been conducted in first world countries such as North America (Hochschild, 1983; Wharton, 1993; Leidner, 1999; Ehrenreich, 2001; Berg \& Frost, 2005; Williams, 2006; Gatta, Boushey \& Appelbaum, 2009; Appelbaum \& Schmitt, 2009) and European countries (Appelbaum \& Schmitt, 2009). As such not all of the ideas explored in this literature apply to the Aotearoa/New Zealand context, particularly in relation to hospitality work where, for example, there is not a strong culture of 'tipping'. Despite these limitations, useful insights can be drawn from the literature in order to understand interactive service work in relation to the triadic relationship, precarious employment, and emotional labour.

\section{The triadic relationship: Getting it on both sides}

Edgell (2011) and McDowell (2009) argue that service work is distinguishable from other forms of work because it is framed by a three directional relationship between employer, consumer and employee. That this relationship exists is well understood in the literature but "it is only in the recent past that research on service sector work has become part of the 'empirical mainstream in the sociology of work'” (Korczynski, 2009, p. 952 cited in Edgell, 2011, p. 119).

Hodson and Sullivan (2012) claim that interactive service sector work can be distinguished from production work because in service work the relationship with the consumer is more immediate. Further to this Edgell (2011) argues that:
"What is distinctive ... about interactive service work is the presence of the recipients of services, which in turn has major implications for the service work role in terms of its emotional and aesthetic style, and complicates the management- worker relationship by introducing a third party whose interests may or may not coincide with those of either workers or their managers" $p$. 121).

In this sense workers in the service sector have to negotiate around the needs of both the customer and the employer: "Because each of these three parties have different criteria for the success of the interaction, the result may be a struggle for the control of the interaction" (Hodson and Sullivan, 2012, p. 237). The implication of this is that the power relations in a service sector workplace can be contested in these three relationships.

\section{Trapped into precarious work}

Vosko et al. (2009) argue that the term 'precarious work' refers to "paid work characterized by limited social benefits and statutory entitlements, job insecurity, low wages and high risks of ill-health” (p. 2). Their definition of precarious work is consistent with the characteristics of many service jobs including those of restaurant wait-staff. The authors also argue that in part-time work precariousness affects women more than men.

McDowell (2001) adds to this gender dimension in her analysis of service sector work. She suggests that bottom end service jobs, or 'high touch' work such as waiting tables, value the traditionally feminine characteristics of servility and deference. She argues that these reinforcing labour market trends reaffirm women's role as the 'servicing class' while providing women with employment that has little job security and an environment of high turnover.

Ehrenreich (2001) provides a rationale to explain how workers become trapped into this type of precarious work. For example, she claims that the laws of supply and demand are ineffective when workers do not have the ability to move and bargain as economic players, due to restrictions from financial pressure, family, geographical location, stereotypes and so on. She suggests that workers stay in these positions of precarious employment where they are unhappy because they lack the ability and the inclination to pursue other employment. Wharton (1993) provides an argument that sheds light on how these workers may lack the capacity to seek alternative employment opportunities. She argues that interactive service jobs can be 'emotionally exhausting' and suggests that possible reasons for increased susceptibility to this exhaustion include aspects such as "low job autonomy, longer job tenure, and ...longer [work] hours" (1993, p. 227). The exhaustion these workers experience, alongside their insecure work conditions, leave workers with a high incentive to hold on to the work they have and little energy to explore alternative employment opportunities. This illustrates the powerlessness that the precarious nature of service work can engender in service workers' lives and how they can become trapped.

\section{Emotional labour: The pleasure and the pain}

Edgell (2011) argues that the social skills required in interactive service work are not present in industrial jobs, and as such the methods of analysis common to industrial jobs either do not reflect or mask the skills present in service sector work. One rich area of research that seeks to address this issue is that emerging from Arlie Hochschild's seminal work The managed heart (1983), where Hochschild used labour process analysis to explore the alienation and exploitation of airline hostesses in relation to emotional labour. Hochschild used observations of airline hostesses in the United States of America to demonstrate the burden that emotional labour places on workers as they participate in both surface- and deep-acting. Surface-acting occurs where the worker presents an outward display of emotion that is not matched by how the worker feels on the inside. Deep- 
acting, while still a performance, presents a spontaneously outward display of emotion that is reflected by an internal emotion deeply held, even if manufactured. Drawing on this tradition, Edgell defines emotional labour as "the management of feeling to create a publicly observable facial and bodily display” (p. 120).

Brook (2009) argues that all workers engage in emotion work that features this reproduction of emotion based acting. However, what is significant about Hochschild's insights is her exploration of what happens to workers when this emotion management is framed by institutional practices. Behaviour in the workplace is underlined by what Hochschild termed as 'feeling rules', i.e. "the pinch between 'what do I feel' and 'what should I feel,'” (1983, p. 57). Hochschild argues that the 'commercialization of feeling' allows the organisation to change a workers own set of feeling rules to the detriment of the workers own self-identity. With this in mind, Hochschild claims that management of the emotion of the worker is in the hands of the organisation, causing a divide between the true identity of the worker and the identity they must portray while working.

In more recent research, Korczynski (2005) has outlined how service workers' performances are directed by the logic of bureaucratization and the logic of customer orientation. The arguments linked to this research claim that, given that the worker is oppressed by both the employer and the customer, the work is far more damaging than other categories of work e.g. manufacturing (Edgell, 2011). Hochschild's work was initially used to argue that service work is exhausting and unrewarding, but a number of investigations have challenged this assumption, particularly in relation to the rewards that many service sector workers report in relation to customer interactions (Hodson and Sullivan, 2012).

Some other critiques of Hochschild's work have opened up lines of argument in relation to agency. Bolton and Boyd (2003) provided a critique of Hochschild's Managed Heart (1983) in their article Trolley dolly or skilled emotion manager? Moving on from Hochschild's Managed Heart. Bolton and Boyd argue that Hochschild's portrayal of power relations in the employment relationship was too one-sided and that emotional labour does not always result in the devastating consequences suggested. Bolton and Boyd propose that workers are not victims of circumstance as portrayed by Hochschild, but are able to independently and consciously make decisions regarding how much effort they will expend when responding to interactions in the workplace. Further to this, Paules (1996) portrays wait-staff as independent entrepreneurs, fighting for their own financial gain. Paules argues that wait-staff are able to resist the power held by their employer and the customer, both subtly within themselves and more overtly in interactions. Paules suggests that even with the servantile way in which wait-staff are treated, wait-staff that Paules encountered viewed themselves as quite separate from the persona they were paid to portray. Through this separation of work and personal identities they are able to use the workplace as a place to conduct their own business (gathering tips), but also as a place where they are able to act autonomously and even leave at will.

Arguing along slightly different lines, Korczynski (2005) suggests that what makes emotional labour harmful is not the emotional labour itself, but the lack of discretion afforded to employees. She argues that front-line service workers do have discretion to allow for the logic of customer-orientation in accordance with variances in customer behaviour, expectations and perceptions that occur during interactions. However, discretion in service work is often limited to what Korczynski (2005) calls 'service recovery', in which the employee resolves customer complaints by taking ownership of an issue. This challenges somewhat Paules' and Bolton's assertions of high levels of agency. Furthermore, Brook (2009) has refuted Bolton's critique of Hochschild, arguing that there is space in Hochschild's theorisation to capture the complexity and contradictions of emotional labour in service work. The divergent views represented by these challenges to, and reinforcement of Hochschild's analysis is what this paper seeks to understand, by examining the work experiences of three young women working as waitstaff in Hamilton, New Zealand.

\section{Methodology}

This study used a qualitative approach, examining the experiences of young women working as wait-staff in restaurants as a case study of service sector work. These experiences were sought in order to understand the nature of emotional labour and the triadic service sector relationship between employers, workers and customers in this setting.

\section{Research question}

Based on the literature review the overarching research question was:

What are the experiences of young women working as wait-staff, and how do those experiences relate to the triadic relationship, and emotional labour?

This question was explored through three in-depth, semistructured interviews. The interview transcripts were analysed from an interpretative perspective, on the premise that the subjective experiences of those working in these positions are what is most important, as opposed to the quantitative view of a structural perspective or the deterministic view of the feminist. Research using an interpretive perspective provides a basis to develop a rich understanding of working conditions and how these are experienced from the participants' point of view.

Three participants were recruited using existing social networks as per the snowball approach, connecting with other potential participants through existing participants (Tolich \& Davidson, 1999). Standard procedures with informed consent were put in place prior to the interview. The in-depth interviews lasted between 35 and 60 minutes, and were conducted by the first author. To preserve confidentiality and protect the respondents, 
pseudonyms were created for this paper to represent the views of the three participants: Tessa, Amy and Jane.

A potential area of conflict (or of strength) that was anticipated in this research was that the first author had previously worked as a waitress in the hospitality service industry. This is important to note because this could result in some bias in the analysis and interpretation of the data. However, this is not necessarily an issue because qualitative research does not seek to represent an objective stance. Another anticipated difficulty was thought to stem from the use of an existing and extended social network for accessing potential participants. The presence of an existing relationship with the first author may have caused potential participants to feel pressured to participate. This was addressed by emphasising potential participants' rights not to participate. There was also concern that the interviews would raise issues for the participants that would make them feel uncomfortable, by exposing them to concepts such as emotional labour. Steps were taken to keep the participants as safe as possible by ensuring the environment was comfortable and that the interview was more like an informal conversation.

\section{Findings}

A number of clear themes emerged from the interviews. First, all three women reported that they had experienced a power differential between themselves and those they come into contact with in the workplace, namely owners/managers, colleagues and customers. Second, it became evident that there was some space within their role as a waitress and within the hospitality workplace environment in which they could exercise discretion. Finally, while the interviews did predominantly unearth negative aspects of service work due to the direction of the interview questions, the women were all able to name aspects of the job that they enjoy, such as the acquirement of knowledge and skills, and enjoyable interactions with pleasant customers.

\section{Power imposed: No space for decision making}

Throughout the interview process, each of the three women clearly described times when they had felt the power of others (employer, colleagues and/or customers) imposed upon them. The subthemes that have been identified are poor management practices, workplace bullying and conflicts, and negative customer interactions.

\section{'Poor management practices'}

The three women all commented on unjust workplace practices such as staff shortages increasing workload, lack of opportunities to rest, and financial losses from errors made by staff and customers.

"We needed at least three staff...from what I can see, not a lot is happening in terms of employing extra people...it's getting really tiring and frustrating"... "I'm certainly the only front of house person who gets a break... No one's asked but it's never been offered either." (Jane)
"I did a mistake one week...she made me pay for the whole bill out of my pay which was about a $\$ 300$ bill and it came out of my pay”. (Tessa)

This was further expressed by the women's thoughts about how owners and managers react to error and don't see 'good works'.

"It's never his fault, it's always the wait-staffs fault"..."He can get pretty irate when mistakes are made." ... "There aren't a lot of opportunities to stop and say 'I really appreciate what you're doing' because it's such a busy industry.” (Jane)

\section{'Workplace bullying and conflicts'}

Conflict and bullying were identified as areas of significant distress and strain by the women. This was reported mainly in relation to how gossip had a negative impact on the management of their shifts, and the bullying ways in which they were spoken to by chefs, owners, and managers.

"I was hanging out with someone... and they got wind of it and I was full time and my hours dropped from 40 to 12 the next week." ... "I hate how it's run...There's a bit [of a] rumour mill going on, she'll find out warped versions and it's hard to keep up sometimes, what my boss is currently thinking about me. It's really stressful waiting for the roster to come out each week when you need money." ... "She'd drop you a day or two. She tried to play us off against each other." (Amy)

"Two of the chefs we have can be quite arrogant and like to think they are a class above, which can create some hostility at times." (Jane)

"The general manager always picked on me the most...they (co-workers) said I did a better job than she did and she could see that." ... "I'm sick of her (general manager) treating me like absolute crap, at the end of every shift I'd be in tears. Even if I was doing a double shift I'd be in tears. That's not right, being called stupid when you've done nothing wrong." ... "If you made a mistake you wouldn't hear the end of it, she'd swear in front of customers at you...she'd stand there and yell at you." (Tessa)

\section{'Negative Customer Interactions'}

Although the women pointedly stated how positive customer interactions can be, they were also all able to recall some interactions with customers that involved them being made to feel invisible, inferior or bullied:

"You get the occasional person that treats you like something on the bottom of their shoe but that's so few and far between it doesn't really warrant... it's not something rooted deeply in society." ... "He used a lot of swearing and profanities...I went and topped up the glass... He did not say thank you, just pretended that nothing had happened." (Jane) 
"A lot of people treat you like they forget that you are an actual human being. A lot of customers are really good, friendly and chatty so it depends." ... "Some of them I can't stand, some of them are so rude and it's just so difficult to actually keep composure."... "I came out to tell him and he was so mad. He stood up so abruptly that his chair flew out behind him; he was yelling at me, spit flying in my face. I think I probably did cry. That was pretty nuts... One of my co-workers had a pie thrown at her once, I don't know why." (Amy)

"Of course you'd have some that were just horrible, horrible people and looked down at you as if you've got the worst job ever but to do your job you've got to push through it." (Tessa)

\section{Power negotiated: Space for decision making}

The women also expressed that there were times during their work in which they were able to make decisions and were able to carry out tasks without coercion. The subthemes we have identified are moments of autonomy, flexibility, emotional labour and identity.

\section{'Moments of autonomy'}

Each of the women was able to exercise some independent decision making regarding the provision of extra food and drink when serving customers, in relation to 'service recovery'. An example of this from Jane when she recalled a story of a customer who was complaining:

"I went and topped up [their] glass."

"With customers I generally try to keep them happy, give them a drink on the house if everything turns bad." (Amy)

"...offer them a drink while they're waiting...so they aren't sitting there twiddling their thumbs." (Tessa)

\section{'Flexibility'}

The three women were all managing multiple roles, such as being students as well as workers. They argued that the flexibility of the service industry allowed for reduced time conflicts between these competing roles. For example:

"When I have assignments they are really good with giving me time off. When you're on their good side it's very good.” (Amy)

\section{'Emotional labour'}

The three women expressed the idea that managing their emotions was quite easy, but did so from the point of view that you have to be friendly to do this kind of job, expressing an acceptance of deep-acting. While they were not aware of the concept of emotional labour they all described behaviours indicative of emotion work.

"I'm generally a happy person, so I think it was quite easy because I'm always smiley.” (Tessa)
“It's just something you've got to do. I think in any job on some level." (Amy)

"You don't have to be enjoying your job but at least you have to pretend you do." (Jane)

A more negative pressure imposed by acting 'happy' when internally you are not (surface-acting) was expressed by Tessa:

"If you have someone terrible that just stresses you out then it puts you in a bad mood and I think customers can see that and feel it when you're not in a good place."

\section{'Identity'}

The three women identified strongly with their workplace and had a clear sense of pride in their work. However, they also indicated that their personal identities were separate to the workplace, for example:

"As a waitress I breeze in at $6.15 \mathrm{pm}$, do what I have to do in my certain section and then leave."... "There is not really the perception that hospitality is something you aspire to...its parttime work on the way to doing other things." (Jane)

"For me it's not full-time work, it's not a big part of my life. It's easy to think when customers treat you bad, 'whatever, this isn't my life, you don't know me, who are you to judge?'” (Amy, emphasis added)

"But people who are high class or whatever will ask what you do, are you a student? They are a bit more lenient because this is just your part-time job and I think they don't look down at you as much because they were in the same boat once." (Tessa)

\section{Perceived benefits: Why do they do it?}

Although the tone of the interviews was often negative, the women all identified positive reasons for working in hospitality. These 'enjoyable aspects of work' included obtaining industry based skills and qualifications, and finding personal enjoyment in positive interactions with customers.

\section{'Enjoyable aspects of work'}

“He (owner) put me through my manager's license to get a duty management certificate because he wanted me to step up and run the place.” (Tessa)

“I like making coffee.” (Amy)

"The knowledge that I've gained about food and wine is really fun." (Jane)

In relation to customers:

"It's nice when customers go up to pay [and] say the waitress was great...you'd always hear that of all the waitresses so it's kind of nice." ... "[I particularly liked] the waitressing, especially 
when you've got fun tables and you can make sure they have a really good night." (Tessa)

"One group in particular...they know me by name, they always ask how I am, how my teaching is going, how my job hunt is going. They are absolutely lovely. I know all about their children and what they're doing. I understand their sense of humour, we can have a little joke and it's really nice." (Jane)

\section{Discussion}

Given there were only three interviews, generalisations cannot be drawn from this research. However, connections can be made between the experiences of the three young women in relation to the literature described earlier.

All three women were upper middle class, pākehā, university students (two of them teachers), giving them a strong clear sense of identity separate from their workplace. This reinforces Paules' argument that the perception of their identity being beyond the workplace enabled them to cope with some of the more negative interactions in the workplace, particularly those with customers. Furthermore, their identity as students also placed them in a position where they felt able to mentally separate themselves from their roles as waitresses, viewing this as a short-term situation, a stop gap before their 'real' career began. This situation meant that their job was more of a 'choice' than the literature on the precarious nature of service work reflects. They were not trapped; rather they were in flexible roles that enabled them to deal with multiple identities and roles.

However, despite their educated, empowered, middle class identity, all three women reported being disadvantaged, often illegally, in their employment relationships. This is consistent with the arguments of Brook, Hochschild, Korczynski, McDowell, Vosko et al. and others who critique precarious service work. This aspect of their vulnerability and their acceptance of disadvantage, such as not receiving holiday pay and having money taken out of their wages due to co-workers mistakes, was surprising to us. These young women are aware of their rights and indicated that they had the ability to get different types of jobs. Why then were they so accepting of the disadvantages that came from their employment relationship? Structurally, that the women are in a patriarchal environment could explain their submissiveness. An alternative explanation, however, is that the threat from the loss of hours of work from arbitrary gossip based reasons shaped their behaviour. If this were true it demonstrates that, despite their separate sense of self, the logic of insecure work still influences these women's approach to the workplace.

It is their strong sense of identity though that forms the basis of one of our insights about the triadic relationship, which is that employers and co-workers are the main source of distress and strain in the working lives of the three young women. Customers feel they are entitled to an expected level of service when they go to a restaurant.
When these expectations are met customers come and go without impacting the staff too much. When expectations of service are violated, customers feel entitled to express their displeasure, frustration, or indignation, often at the expense of the staff. Therefore, customers can cause distress and strain, but in terms of these three women's experiences the distress and strain caused by customers was not as great as that caused by co-workers and management. The issues the customers present can be palmed off to a superior or rationalised away as meaningless, because what the customers see is not the 'real' version of who the young women are. Thus the young women protect themselves from the worst effects of emotional labour by their ability to detach themselves from their identity as wait-staff.

In contrast, relationships with co-workers are permanent and based within a hierarchy. Thus a negative interaction can have repercussions long after the original incident occurs. It is the workplace hierarchy, and the challenges of roster management and conflict between the front of house staff and kitchen staff, that made the young women's lives difficult. In fact, much to our concern many of their stories indicated that systematic bullying, often in the form of verbal abuse, was a significant part of what the young women have to 'manage' when they are at work, and often when they are not. This verbal abuse, as well as the removal of rostered hours, seemed to be used by management to shape the young women's behaviour in the workplace. This bullying provides evidence of patriarchal practices and, along with the insecurity of work time, offers an explanation for the women's passive acceptance of such outrageous disadvantage. The other implication of this finding is that, while the young women are part of a triadic relationship where both customers and management/owners can and do exploit the young women, the exploitation experienced through their relationship with management is far greater. It is this finding in particular that challenges somewhat the emphasis some writers such as Korczynski and McDowell place on all three parties to the triadic relationship.

Another main area we sought to focus on was 'Emotional Labour'. All three women acknowledged that the need to alter feelings was part of their job. What was interesting about this insight was that they did not seem to perceive this as differing from natural interaction in any way. They only found this emotion work troublesome if they were already in a negative mood, in which case they consciously altered the appearance of their mood in order to appease customers and/or other staff/management. However, they were still able to resist the logic of bureaucratisation in their thoughts and in conversations with other employees, displaying the surface-acting of Hochschild's analysis. Their experiences seem to reinforce the ideas of Bolton and Paules around the concept of agency which, given their class and level of education, is as expected. This means that the findings challenge the more fixed categorisations of Hochschild's emotional labour and reflect the young women's ability to resist the requirement to be 'happy', and their ability to exercise agency in their emotional labour. 
What was straightforwardly similar to literature was that customers were best part of their job. All three women were able to recall times in which they had encounters with customers that they enjoyed, not just in their role as a waitress but as a person, interacting with others. Sharing humorous moments, small talk and sometimes even a form of friendship with regular customers, were reported to be aspects of the job that the women found enjoyable. All three women enjoyed the skill acquisition that they had accessed through their positions as waitresses. This included barista skills and even formal qualifications (e.g. bar manager's license). They also reported having fun while on the job and forming positive social relationships with colleagues. However, it is perhaps this part of their workplace collegiality that makes the young women so much more vulnerable to the actions of their colleagues than those of customers. It is far more difficult to manage the emotions linked to a space were the staff members are not interchangeable but instead are permanent. Furthermore, their workplace identity is a shared identity with others in their workplace and as such it may not be as easy to dismiss negative feedback from managers and co-workers. Overall, the young women demonstrated work lives of considerable pleasure but also disadvantage, and while explanations of this acceptance of bullying can be made it certainly does not make it acceptable. This is especially true because the education and middle class identity of these young women protects them, but these protections are not available to those who are not skilled and are not middle class.

\section{Conclusion}

Work in the service sector is tough, and not just in the physical sense as is the common perception. These individuals work in an industry that requires not only physical but mental and emotional labour. Furthermore, the work of wait-staff is often unjustly perceived as low skilled and low status. We argue that it is imperative that society recognises and gains a better understanding of the working experiences of wait-staff, as these workers are largely under-appreciated, undervalued by employers and customers alike, and are under-represented in the literature.

The experiences of these three young women demonstrate that the triadic relationship definitely plays a role in exploitation and alienation, but that power relations are still governed primarily through the employer-employee relationship. Furthermore, in order to access positive workplace experiences such as flexible work, knowledge and fun, these young women were prepared to put up with substantial levels of bullying. This indicates that the young women engage in surface- and deep-acting with their managers and co-workers far more than with customers. These three young women's experiences of the triadic relationship were both positive and negative. Their ability to negotiate around the demands of emotional labour stemmed from the strength of their other identities as being middle class and educated. This suggests that some service sector workers can exercise agency, but this assertion needs to be tempered by the acknowledgement that not all workers have access to multiple identities.

\section{Acknowledgements}

The authors would like to thank Dr. Michael Cameron for helpful comments on earlier drafts of this paper and the LEW conference participants for indicating new areas of analysis in relation to structural factors such as patriarchy.

\section{References}

Anderson, B. (2002). Just another job? The commodification of domestic labour. In Ehrenreich, B., and Hochschild, A. R. (2002). Global woman: Nannies, maids, and sex workers in the new economy. New York: Henry Holt and Company.

Appelbaum, E. and Schmitt, J. (2009). Review article: Low-wage work in high-income countries: Labormarket institutions and business strategy in the US and Europe. Human Relations, 62, 1907-1934.

Berg, P. and Frost, A. C. (2005). Dignity at work for low wage, low skill service workers. Relations Industrielles, 60, 657-682.

Bolton, S. and Boyd, C. (2003). Trolley dolly or skilled emotion manager? Moving on from Hochschild's Managed Heart. Work, Employment and Society, 17, 289-308.

Brook, P. (2009). In critical defence of 'emotional labour’ refuting Bolton's critique of Hochschild's argument. Work, employment and society, 23(3), 531-548.

Careers NZ. (2006). Major industries in New Zealand. Retrieved from http://www2.careers.govt.nz/jobsdatabase/whats-happening-in-the-jobmarket/major-industries-in-new-zealand/

Edgell, S. (2011). The sociology of work: Continuity and change in paid and unpaid work. London: Sage Publications.

Ehrenreich, B. (2001). Nickel and dimed: On (not) getting by in America. New York, NY: Henry Holt and Company.

Gatta, M., Boushey, H., and Appelbaum, E. (2009). High-touch and here-to-stay: future skills demands in US low wage service occupations. Sociology, 43, 968-989.

Hochschild, A. R. (1983). The managed heart: Commercialization of human feeling. Berkley: University of California Press. 
Hodson, R. and Sullivan. T. A. (2012). The social organisation of work. Belmont: Wadsworth, Cengage Learning

Korczynski, M. (2005). Skills in service work: An overview. Human Resource Management Journal, 15(2), 3-14.

Korczynski, M. (2009). The mystery customer: Continuing absences in the sociology of service work. Sociology, 43(5), 952-967.

Leidner, R. (1999). Emotional labour in service work. American Academy of Political Science, 561, 8195.

McDowell, L. (2001). Father and ford revisited: Gender, class and employment change in the new millennium. Transaction of the Institute of British Geographers, 24, 448-464.

McDowell, L. (2009). Working bodies: Interactive service employment and workplace identities. West Sussex: Wiley \& Sons.

Paules, G. F. (1996). Resisting the symbolism of service among waitresses. In MacDonald, C. L. and Sirianni, C. (1996) Working in the Service Society. Philadelphia: Temple University Press.

Ritzer, G. (1996). The McDonaldization of society: An investigation into the changing character of contemporary social life. Thousand Oaks: Fine Forge Press.

Ritzer, G. (1998). The MacDonalization thesis: Explorations and extensions. London: Sage Publications.

Tolich, M., \& Davidson, C. (1999). Starting fieldwork: An introduction to qualitative research in New Zealand. Auckland: Oxford University Press.

Vosko, L. F., MacDonald, M. and Campbell, I. (2009). Gender and the contours of precarious employment. New York: Routledge.

Wharton, A. S. (1993). The affective consequences of service work: Managing emotions on the job. Work and Occupations, 20(2), 205-232.

Williams, C. (2006). Inside toyland: Working, shopping and social inequality. Berkeley: University of California Press. 